\title{
RELIGIOUS PLURALISM AND THE BURIDAN'S ASS PARADOX
}

\author{
JONATHAN L. KVANVIG
}

Baylor University

\begin{abstract}
The paradox of Buridan's Ass involves an animal facing two equally adequate and attractive alternatives, such as would happen were a hungry ass to confront two bales of hay that are equal in all respects relevant to the ass's hunger. Of course, the ass will eat from one rather than the other, because the alternative is to starve. But why does this eating happen? What reason is operative, and what explanation can be given as to why the ass eats from, say, the left bale rather than the right bale? Why doesn't the ass remain caught between the options, forever indecisive and starving to death? Religious pluralists face a similar dilemma, a dilemma that I will argue is more difficult to address than the paradox just described.
\end{abstract}

The paradox of Buridan's Ass involves an animal facing two equally adequate and attractive alternatives, such as would happen were a hungry ass to confront two bales of hay that are equal in all respects relevant to the ass's hunger. Of course, the ass will eat from one rather than the other, because the alternative is to starve. But why does this eating happen? What reason is operative, and what explanation can be given as to why the ass eats from, say, the left bale rather than the right bale? Why doesn't the ass remain caught between the options, forever indecisive and starving to death? ${ }^{1}$

Religious pluralists face a similar dilemma, a dilemma that I will argue is more difficult to address than the paradox just described. According to religious pluralists, there is enough truth in any religion (or perhaps some special subset of religions, such as the major world religions) to yield the soteriological benefits promised by the great religions of the world.

${ }^{1}$ Originally, the point was not taken to generate a paradox, but rather a reductio of John Buridan's theory of free choice, where freedom could consist in inaction, in the ability to defer for further deliberation any decision that isn't absolutely certain. The example is not discussed by Buridan, but can be found as early as Aristotle's De Caelo 295b32.

European Journal for Philosophy of Religion i (2009), pP. I-26 
This great good is available, not solely on the basis of allegiance to some particular religion, but to any among several. Religious pluralists need not hold that any religion is as good as any other, or that every religion is suitable for obtaining such a great good. They do hold, however, that there is more than one tasty religious bale of hay in sight.

\section{The Standard Taxonomy and Its Discontents}

The usual classification scheme in which pluralism finds its home divides options into exclusivism, inclusivism, and pluralism ("the EIP scheme," as I will refer to it). An initial clarification can be made with an example. Suppose there are two religions, Christianity and Buddhism, and we use the term "heaven" to refer to whatever great good a religion offers. Pluralists think both Christians and Buddhists attain heaven in virtue of adhering to their own home religion, exclusivists think that only one of the two can attain heaven (in virtue of adhering to the one true religion), and inclusivists think that both Christians and Buddhists can attain heaven (in virtue of the truth of the one true religion). Suppose, then, that it is Christianity that is the true religion. A Christian exclusivist bars Buddhists from heaven (so long as they do not convert to Christianity), while a Christian inclusivist claims that Buddhists can go to heaven, but any Buddhist in heaven will be there because of the work of God in Christ making it possible.

This example helps to explain the general character of the classification scheme. More generally, let us begin with a distinction between alethic and soteriological adequacy. A religion is alethically adequate if and only if the claims of the religion are true. It is soteriologically adequate if and only if it is effective in securing the great goods religions claim are available for their adherents (which I will refer to here as "salvation," though without intending anything beyond reference to the great goods in question). Using this distinction, we can understand the positions in question in terms of what they say about the relationship between truth and salvation. Exclusivists lean toward a one-to-one correspondence between alethic and soteriological considerations, tending to hold that salvation depends on the truth of the view in question and one's adherence or commitment to this truth. Pluralists of the simple variety view 
alethic and soteriological considerations as relatively unrelated, so that pretty much any religion, or any major religion, is as good as any other at securing soteriological goods. Inclusivists fall somewhere in between these two options, holding that the explanatory basis of an adequate soteriology depends on the truth of some particular religious viewpoint, but denying that commitment to the truth in question must be present for soteriological benefits.

The most difficult position to clarify in this scheme is the inclusivist position. A typical explanation of this position starts with an adherent of a particular religion, e.g., Christianity, who does not want to endorse the harsh view that the vast majority of human beings will not go to heaven. So, suppose such a Christian holds that not only Christians, but also Muslims and Jews and Hindus and Buddhists, as well as representatives of other religions, will make it to heaven. Suppose that such a Christian holds that such individuals make it to heaven, however, not on the basis of their commitment to their own, home religion but rather because of the work of God through His Son, Jesus. They are, some will say, "anonymous Christians." 2 That is, such a Christian denies the efficacy of any religion other than Christianity in securing heaven for anyone; this imaginary Christian holds, however, that many non-Christians will nonetheless be in heaven because adherence to the one true religion is not required for salvation.

I'll say something in a moment about the vagueness and messiness of the EIP scheme, but first I want to distinguish it from a different one which emphasizes the degree to which one's account of salvation is revisionary with respect to extant religion. Revisionists about religion come in two varieties, but both count as versions of exclusivism. Some revisionists think that each religion has a logical core and that the core commitments of the major religions are all compatible with each other. Such "logical core" revisionists count as exclusivists, since they align alethic and soteriological considerations, explaining soteriological consequences in terms of commitment to the logical core of whichever religion one endorses. Logical core revisionism is an all-but-dead theoretical option, however, since it is fairly conclusively refuted by empirical considerations.

2 This is Karl Rahner's phrase; see Foundations of Christian Faith: An Introduction to the Idea of Christianity, translated by William V. Dych (New York: The Seabury Press, 1978). 
Any reasonable account of the core commitments of the major religions shows that they disagree with each other. ${ }^{3}$

A different kind of revisionary view is syncretism, according to which none of the major religions is true as it stands, but each contains true elements which can be combined into a correct account of religious reality. Syncretism tends to be a version of exclusivism, though the matter is a bit more complicated since, strictly speaking, most human beings will never have thought of the syncretism in question. Syncretists can go in several directions here. One option is to endorse the pessimistic view in which my religious ancestors delighted: that most of humanity is damned for lack of exposure to the truth. More appealing from a moral point of view, though, is the option according to which one relaxes the idea of what is required to adhere to the one true religion, counting the faintest glimmer of insight as sufficient for adherence to the syncretistic truth.

It is here that the messiness of the EIP scheme becomes obvious. On this scheme, positions are distinguished by what they say about two items. One concerns the salvific adequacy of a particular religious form of life, and the other concerns the alethic adequacy of a view and the kind of commitment required toward that view. Exclusivists are identified as those who hold that there is one correct religion, and that doxastic commitment to it is necessary for the salvific adequacy of such a form of life. Yet, when put this way, it is hard to think of any examples of exclusivism. If we take Christianity as the example and assume it to be true, there is no major Christian position that requires adherence to the entire truth as a condition for salvation. Exclusivist Christians, of course, claim that one must be a Christian in order to be saved, but the doxastic commitments required are rarely specified precisely, and with good reason. As soon as precision comes into the picture, counterexamples in the form of Abraham, Isaac, and Jacob threaten the account, even if articulators of

3 There is a different use of the notion of the logical core of a religion that is unobjectionable. Any given religion can have multiple manifestations in terms of denominations, sects, cults, etc. Each such manifestation differs in doctrinal commitments, and thus we might seek the logical core of a religion. Adherents of a given manifestation may thus grant that adherents of other, e.g., denominations, may go to heaven in virtue of commitment to the logical core of the true religion. As I use the term "logical core revisionism" in the text, this appeal to the logical core of a religion doesn't constitute an instance of logical core revisionism. 
a given precisification are willing to bite the bullet on the eternal destiny of saints of other religions.

We can adopt this scheme if we refuse to pretend that it removes all vagueness from our categorizing. Vagueness is nearly everywhere in language, and though precisification is often helpful from a theoretical perspective, we can often make progress without it. A clear example of vagueness occurs when a syncretist allows the faintest glimmer of recognition of truth to be salvifically adequate. How should we classify this view? In some respects, it looks like inclusivism, since a practicing Christian, or Jew, or Hindu, could achieve salvation but only because of the truth of the syncretistic view in question (which is, by hypothesis, incompatible with each of the faiths in question). In another respect, it looks very much like certain positions that one is inclined to classify as exclusivist. Most traditional Christians have maintained that the saints in the Old Testament are saved, but it is impossible to identify any distinctively Christian commitments of such individuals. That they had such beliefs would be a suggestion for which there is very little evidence. The usual explanation told here by traditional Christians cites the glimmer of understanding such individuals possessed, plus their faith in and commitment to the God of the Abrahamic traditions. The point to note, however, is the similarity here with what the syncretistic position in question maintains: namely, that the faintest glimmer of a grasp of truth is enough by way of doxastic commitment to make salvation possible.

I will not attempt here to resolve this vagueness in the EIP scheme, for my interest is not in the distinction between inclusivism and exclusivism but rather in the distinction between both of these and pluralism. On this score, the EIP scheme is less troubling, since one can sort the pluralists from the remainder simply in terms of whether some commitment to the truth is part of the soteriology advanced.

A caveat remains in order nonetheless. Things can become complicated and difficult to manage if what looks like pluralism is combined with unusual claims about truth. For example, consider John Hick's Kantian account on which the major religions are thought of in quasi-Kantian terms as different phenomenal windows on the same ultimate noumenal reality. The proper way to categorize this view depends on what it says about truth. To be thoroughly Kantian, the view will have to think of truth in terms of the phenomenal realm, but that turns out to require, to understate the 
point, a rather lengthy detour into the logic of inconsistency (since, at what Hick terms the phenomenal level, we find all the particular claims of the various religious, claims that are obviously inconsistent with each other). Though Hick flirted with the idea that the salvation of his view lies in the direction of exploring such a logic, ${ }^{4}$ it is hard to take seriously, even in a time when dialetheism has become a serious philosophical position. ${ }^{5}$ The problem is that, when truth is conceived in Kantian fashion as pertaining to the phenomenal realm and one holds that all religions (or major religions) are alethically as well off as any others, there are way more contradictions than even dialetheists are willing to countenance. If one can swallow all the contradictions, such a view counts as a version of exclusivism, since it is in virtue of commitment to the truth that salvation is achieved. But, oh, the pain of swallowing.

Easier on the digestive system is the view that characterizes truth in terms of the noumenal realm, leaving Hick's view as a version of pluralism, since none of the phenomenal claims can strictly accord with the noumenal truth. When combined with Hick's view that all the major world religions are equally good from a soteriological perspective, ${ }^{6}$ the view that results is paradigmatically pluralistic. ${ }^{7}$ On this view, salvific adequacy for a view comes apart about as radically as is possible from any requirement of doxastic commitment to the truth.

As briefly indicated already, I will talk here in terms of the existence of God and the salvific promise of heaven, rather than in terms of some great good available for human beings and attachments to the Real with a capital 'R', but I want it to be understood that such language is not meant to restrict the options that pluralists might have in talking about

${ }^{4}$ The speculation about logics of inconsistency can be found in Hick's contribution to The Philosophical Challenge of Religious Diversity, edited by Kevin Meeker and Philip Quinn (New York: Oxford University Press, 1999), "Religious Pluralism and Salvation," 54-66.

5 See, e.g., Paraconsistent Logic, ed. G. Priest, R. Routley and J. Norman (Amsterdam: Philosophia Verlag, 1989).

6 See, e.g., John Hick, An Interpretation of Religion (New Haven, Conn.: Yale University Press, 1989) and Disputed Questions in Theology and the Philosophy of Religion (New Haven, Conn.: Yale University Press, 1993).

7 To continue the metaphor in the text, we still don't have a simple gustatory delight, however. The claim that all religions are phenomenal windows on the same ultimate noumenal reality is itself both true and about the phenomenal realm, it would seem. But if nothing about the phenomenal realm is true, then this claim can't be true either. 
religious goods. I will speak of God and heaven for the sake of simplicity, leaving open the option that a religious pluralist might hold that the religious good in question does not involve theism or an afterlife (and leaving open the option that the great goods in question obtain both in the present and in the life to come). All that is essential to the position is a denial of the claim that adherence to some one true religion is necessary for securing the great goods that religions proffer, however cognitively feeble that adherence might be conceived to be.

I also leave open whether there is one great good that adherents of all the acceptable religions are successful in achieving. An imaginable position, though one hard to find any serious defense of, is relativistic pluralism, according to which the great good achieved varies depending on the religion to which one adheres. Perhaps some religions are useful in achieving Nirvana and others in securing heaven as understood by Christians. Nothing said here will presume any position on the issue of relativism for pluralists.

The point of this terminological digression is to make clear which view I want to discuss when talking about pluralism. It is easy to see why pluralism is different from exclusivism, but a bit harder to distinguish from inclusivism. My discussion here is meant to provide a basis for distinguishing relatively inclusivist adherents of a religion ${ }^{8}$ from the focus of this paper, as well as to separate revisionary and syncretistic views from pluralist views. Neither inclusivist nor revisionary views are the target of the present essay, but only those who believe acceptability to God and resultant presence in heaven can be achieved on the basis of adherence to any of a number of religions, with no religion having a special status which makes it soteriologically superior to any other religion, and where the explanation of soteriological adequacy does not advert to the distinctive claims of any religion at all. For pluralists, the cognitive dimension of the religious life

${ }^{8}$ I use the relativity qualifier since the difference among inclusivist and exclusivist Christians here is a matter of degree. Even the staunchest exclusivist Christians believe that some adherents of the Jewish faith will be in heaven, in spite of having no acquaintance with Jesus and no allegiance to any of the core teachings of Christianity about Jesus, his birth, life, death, and resurrection: for example, the great figures of the Old Testament. Some of these Christians also endorse a dispensationalist story as to why no one who lives after the time of Jesus has the same opportunity, but the point remains that they must interpret the "no other name" passage so that presence in heaven does not require, in one's earthly life, any particular mental attitude toward that first-century person in Palestine. 
may be necessary to the entire experience of religiosity but the truth of the claims is explanatorily otiose regarding the question of salvific adequacy.

Pluralists, unlike inclusivists and exclusivists, must face the paradox of Buridan's Ass. For they believe that achieving heaven is a surpassing good, but also hold that there are a number of different paths to it. So, which path should a fully informed and rational individual take? Or is the result the damnable analogue of Buridan's ass starving to death through the inability to make a rational choice? We can begin to address this issue by considering the structure of a solution to the paradox conceived as an attack on the possibility of rational action in such a situation.

\section{Reasons and Contrastive Reasons}

Here's what we know about the version of the paradox I'll explore here: a proper theory of rationality does not require the ass to starve to death. The concept of rationality I'll focus on here is a teleological one, identifying items as rational when and only when they are appropriately related to the relevant goal in the domain in question. I will assume here that the epistemic goal can be explained in terms of the concept of truth and that the practical goal can be clarified in terms of self-interest or well-being. Given these assumptions, we can easily see that it is contrary to the well-being of the ass to opt for starving to death in such a situation, and so we know that a correct theory of rationality will not require the ass to remain in a state of indecision forever. Hence, it follows that it is not irrational for the ass to eat from either bale. What we should say about the question of explanation, the question of why the ass eats from, say, the left bale rather than the right, is left open at this point. What is not left open, however, is whether it is rational for the ass to starve to death.

From this point, some theorists will want three categories and some two. Some will want to classify actions into rational, nonrational, and irrational, while others will want to speak only of rational and irrational actions. One motivation, in my view, the primary one, for wanting three categories is to avoid having to count arbitrary actions as rational, where an arbitrary action is defined as one of several actions possible for the circumstances in question, where no reason can be found, relative to the goal in question, for preferring that action to its competitors (as in the paradox). 
This argument for the existence of three categories can be rebutted by the following considerations. First, note that a theory of rationality should be perfectly general, applying both to actions and mental states (beliefs, desires, hopes, wishes, etc.). In the domain of belief, however, the threat of skepticism looms large if one is willing to endorse a connection between reasons and contrastive reasons. In the former case, we speak of having a reason to believe some claim $p$; in the latter case, we speak of having a reason to believe $p$ rather than $q$, where $q$ is an alternative to $p$ (i.e., is a member of a set of claims including $p$ where each member excludes all other members and where the set is exhaustive in the sense that some member of the set must be true). In the case of the Buridan's Ass Paradox, we may be inclined to say that the ass has no reason to eat from, say, the left bale because it has no reason to eat from the left bale rather than the right. To say such a thing is to endorse a connection between reasons and contrastive reasons, and an analogue of such a connection in the realm of belief is:

Reason $\mathrm{R}$ is an adequate reason to believe $\mathrm{p}$ only if, for any alternative

$\mathrm{q}$ to $\mathrm{p}, \mathrm{R}$ is an adequate reason to believe $\mathrm{p}$ rather than believe $\mathrm{q}$. Such a principle threatens one with skepticism almost immediately. Suppose you have a visual experience of a red object on the table, and believe as a result that there is a red object on the table. Is your experience an adequate reason for your belief? By the above principle, it is so only if it is an adequate reason for believing that there is a red object on the table rather than that there is a black light shining on a non-red object, making it appear red. If the experience is a contrastive reason of this sort, it is also an adequate reason for believing that there is no black light shining making the object appear red when it isn't. Yet, if the question arises whether appearances are deceiving in this way, it would be pathetically bad epistemic practice to cite the very experience itself to assuage such concerns.

The problem of explaining how one can know that appearances are not deceiving in this way has come to be called the Problem of Easy Knowledge. ${ }^{9}$ Various proposals have been developed in response to the

9 The first formulation of the problem is by Stewart Cohen, "Basic Knowledge and the Problem of Easy Knowledge," Philosophy and Phenomenological Research 65 (2002): 309-329. 
problem, ${ }^{10}$ but whatever the proposal, any plausible approach to the problem will require denying the principle above. Adequate reasons for belief do not have to be adequate contrastive reasons for belief, and thus, in this limited sense, beliefs can be both arbitrary (in the technical sense described above) and yet rational. Perhaps acquiring an adequate reason for thinking that appearances are not deceptive in the way imagined is not especially difficult-for example, perhaps all one needs to do is to look briefly at the lighting in the room to acquire an adequate reason for thinking that there is no black light causing deceptive appearances. Perhaps, as well, there are other ways in which reasons and contrastive reasons align themselves-for example, even though in general, reasons don't need to be contrastive reasons, perhaps they must rule out alternatives that are psychologically salient in the right way. This possibility will become important later in our discussion, but for now the important point to note is that neither of these points rescues the claim that reasons must be contrastive reasons in the theory of rational belief.

Given that a theory of rationality ought to be fully general, we should expect the same result in the theory of rational action. If we find the same result there, then we can say that arbitrary actions, too, can be rational, i.e., that reasons for doing $\mathrm{A}$ need not be reasons for doing $\mathrm{A}$ rather than $\mathrm{B}$ for any competing alternative $\mathrm{B}$ to $\mathrm{A}$. In this way, the case for a category of nonrational actions or beliefs on the basis of considerations of arbitrariness (where arbitrariness is understood in limited fashion in terms of a denial of a perfect correlation between reasons and contrastive reasons) is undermined. It is not true, in general, that arbitrariness is incompatible with rationality.

This argument can be summarized concisely as follows. First, define arbitrariness in terms of the failure of a requirement that an adequate reason be an adequate contrastive reason. Second, note that if arbitrary beliefs can be rational, then we should expect that arbitrary actions can be rational. Third, consider the Problem of Easy Knowledge, and the way in which it demonstrates that arbitrary beliefs can be rational, i.e., that

10 See, e.g., Peter Klein, “Closure Matters: Academic Skepticism and Easy Knowledge," Philosophical Issues I4 (2004): 165-184; Peter Markie, "Easy Knowledge," Philosophy and Phenomenological Research, forthcoming; Ram Neta, "A Contextualist Solution to the Problem of Easy Knowledge," in manuscript; Ernest Sosa, "Response," in Ernest Sosa and His Critics, ed.John Greco (Blackwell, 2004), especially his response to Cohen. 
an adequate reason for belief need not be an adequate contrastive reason. Finally, note that the particular kind of action for which a category of nonrationality was desired is arbitrary actions that fail to be irrational. But if arbitrary beliefs can be fully rational, as they must on pain of having to endorse radical skepticism, then arbitrary actions can be as well. Thus, there is no reason based on this kind of arbitrariness to refuse the conclusion that when such an arbitrary action fails to be irrational, it is rational.

\section{Arbitrary Actions and Arbitrary Choices: A Start on Solving the Paradox}

This conclusion allows for the possibility of a solution to the Buridan's Ass Paradox. If the ass eats from either bale, there will be no adequate contrastive reason for doing so. Yet, if reasons don't need to be contrastive reasons, that allows for the possibility that the eating is rational nonetheless. It doesn't matter which bale the ass eats from, for the action involved will be rational either way.

Pointing out the difference between a reason and a contrastive reason doesn't tell us much about the general theory of rationality that might include such a distinction. Moreover, even describing vaguely the contours of such a general theory is difficult, but it is worth noting in this regard that there is a contrastive reason available at a higher level of generality, since there is an adequate reason for the ass to eat from one of the two bales rather than starve. Perhaps the more specific action inherits its rationality in the absence of support by a contrastive reason from the higher-order contrastive reason, even though whichever specific token of the general type is displayed, that token will count as an arbitrary action. In any case, whatever general account is given, it remains the case that arbitrary actions can be rational, so we can't argue that the ass fails to be rational for eating from the left bale simply because that action is an arbitrary one.

As pointed out, both beliefs and actions can be arbitrary and yet rational. But the notion of arbitrariness here is a technical one, defined in terms of the distinction between adequate reasons and adequate contrastive reasons. This sense of arbitrariness raises no particular problems for the pluralist: the pluralist is in the position of Buridan's ass, and rationality can accompany whatever choice is made. 


\section{Pluralism and Arbitrariness}

The problem for the pluralist arises, however, when we think about other notions of arbitrary actions and beliefs. The notion of arbitrariness clarified to this point allows that a factor can confer rationality on an action or belief without conferring irrationality on competitors of that action or belief. It is compatible with this point, however, that there are important differences between the rationality of action and the rationality of belief as to why reasons don't have to be contrastive reasons. As a motive for considering this possibility, notice that even though we talk about the choice of a religion in much the same was as we talk about the choice the ass faces regarding which bale to choose, the language of choice may not be altogether appropriate in the realm of religious affiliation. To become an adherent of Christianity is not simply a matter of choosing to attend Mass or to attend confession or to be baptized. Essential to the story is a matter of cognitive commitment, a coming to view the claims of Christianity as true and important. Regarding cognitive commitments, however, the language of choice presents difficulties. I am sitting in a coffee shop and look up, and come to the view that my friend Robert has just arrived. To say that I looked up, considered the possibilities and chose to view the situation as one involving Robert's presence is thoroughly wrongheaded. In this case, no choice of any sort was involved. Instead, the belief resulted because of perception, and the process involved is of a general causal sort. Any reconstruction in terms of the language of choice would be mistaken.

Perhaps these same points apply to the cognitive commitments involved in becoming an adherent of a religion. One can choose to perform the actions associated with being an adherent of a religion, but it may be that one must also come to see the claims central to that religion as ones that are true in much the same way as I came to see that Robert just walked in to this coffee shop. It may be, that is, that the language of choice is simply inappropriate in the context of the cognitive commitments required to be an adherent of a religion.

Notice as well that the way in which reasons don't need to be contrastive reasons differs in the cognitive realm from the practical realm. In the case of the paradox, the ass can rationally eat from the left bale while fully aware of the equal attractiveness of the right bale. But the same kind of 
claim isn't very plausible about cognitive commitments. It is true that Newton can't be charged with irrationality in belief simply because his evidence is compatible with general relativity theory, but it is not true that Holmes can rationally believe that the butler did it while being fully aware that his evidence is neutral between the butler or the baker having done it. Just because a reason doesn't have to be a contrastive reason doesn't imply that reasons can fail to be contrastive reasons in precisely the same way for both beliefs and actions. Since the religious pluralist faces a set of alternatives most obviously similar to that of Buridan's ass, using the solution to the paradox outlined above would commit the pluralist to the view that the kind of arbitrariness tolerable regarding rational cognitive commitments is the same as that regarding rational action. Since such a presupposition is false, the pluralist cannot escape the problem raised by the paradox in the same way that the paradox itself can be dissolved.

Thinking about the differences in the examples of Newton and Holmes reveals differences that are in part psychological: Newton hasn't even so much as conceived of general relativity theory whereas Holmes is imagined to be fully aware of the fact that his evidence is neutral with respect to the guilt of either the butler or the baker. Once we begin to think along these lines, the question becomes one of examining the psychological conditions under which the conferring of rationality is blocked by the presence of competitors that these factors do not rule out. In the case of belief, from the purely theoretical perspective of getting to the truth and avoiding error, the salience of a competitor not ruled out by one's evidence is often sufficient grounds for preventing the rationality of belief. Perhaps Newton can be excused for not withholding when it would be senseless to hold him responsible for considering relativity theory, but you're not likely to be impressed by Sherlock's reasoning if he admits that his evidence leaves open whether it was the butler or the baker and he believes and asserts that it is the butler nonetheless.

This difference is important, because if beliefs are not actions in this sense, one cannot follow the pluralists' advice of just arbitrarily selecting one. Cognitive commitments are central to adherence to a religion, and cognitive commitments are subject to stronger constraints on arbitrariness than are actions.

If pluralism is a mistaken view, there is a straightforward way to answer the question about how to go about selecting a religion: find the true one! 
Some find it harder than others to arrive at a conclusion in such matters, but once one comes to see a certain religion as the true one, there is no mystery left about the cognitive commitments needed for allegiance to that religion. In seeing a particular religion as the true one, one has thereby made the cognitive commitments necessary. There is no guarantee that this process will itself impart rationality to the beliefs that result, but the important point to note here is that the process as so described does not guarantee irrationality in the way that Holmes's admission that the evidence is equally well-explained by the guilt of either the butler or the baker guarantees the irrationality of his view that the butler did it.

Since resolution for the religious pluralist is more like the resolution for Holmes of who committed the murder than it is like the situation of the ass who needs to avoid starvation, the kind of arbitrariness tolerable in a solution to the paradox is inapplicable to the situation of the religious pluralist in trying to secure the great goods that religion offers. This point raises an interesting quandary: if religious pluralism were true, could there be any rational religious pluralists in heaven? For if pluralism is correct, it is through adherence to any of a number of religions that one secures heaven. And adherence to a religion involves cognitive commitments implying seeing the world in a certain way, but religious pluralists will have difficulty being characterized by such commitments so long as commitments track rationality. To be characterized rationally by such commitments, a pluralist would have to commit cognitively to the central claims of some religion or other, but a pluralist also believes that no religion is soteriologically privileged over any other. Thus, the pluralist maintains that whatever cognitive commitments are involved in being an adherent of a particular religion are inessential to the soteriological efficacy of that religion. Yet, most religions include some uniqueness claim, to the effect that the path of salvation is tied to the claims of the particular religion in question and that being on the path of salvation involves recognizing this point. Religions typically claim, that is, that endorsing the claims preached by that religion is essential to salvation. The pluralist, however, endorses a meta-dogma as well, one that says that alethic commitments come apart from salvific adequacy.

It looks, then, that the possibility of a pluralism that is both rational and effective in terms of access to heaven rests on the possibility of inconsistent rational beliefs or on the possibility of finding a religion 
that treats the meta-dogma in question as optional for adherents of that religion. Other options do not hold much promise, since the pluralist, as understood here, doesn't wish to become revisionary about religion itself. So it is not an option here for a pluralist to join a religion and then adopt an unusual construal of what is important from the perspective of that religion. Nor is it a very plausible route to take to insist that there are as many religions as there are noses of the religiously inclined, in order to allow the pluralist to have a set of beliefs adequate for salvation no matter what the content. Instead, religious pluralists wish to show respect for actual religions, at least the major world religions, and to do so, they need to avoid being revisionary or relativistic in these ways. Thus, their hopes ride on the possibility of inconsistent rational beliefs (where the dogmas of the endorsed religion are inconsistent with the meta-dogma definitive of religious pluralism) or of finding a religion that treats the meta-dogma in question as optional for adherents of that religion.

Neither route is promising. About the possibility of inconsistent rational beliefs, I will say very little. It is important, though, not to take refuge here in either the epistemic paradoxes or the possibility of opaque belief contents. In the paradoxes, especially the preface paradox and the lottery paradox, ${ }^{11}$ a common approach claims that the lesson of the paradoxes is that rational inconsistent beliefs are possible. Rational inconsistent beliefs of this sort, however, depend in an important way on the size of the lottery and the sophistication of the book under discussion. If the lottery has only two tickets, one can't rationally believe that some ticket will win and that one's own ticket will lose. If the book has only two claims in it, one can't rationally believe each claim in the book plus believe the preface claim that there are mistakes in the book. Here, size matters. In the case of religious pluralism, the needed analogy is missing. Pluralists

${ }^{11}$ For further information on the epistemic paradoxes, see Jonathan L. Kvanvig, "The Epistemic Paradoxes," Routledge Encyclopedia of Philosophy, 1998. The lottery paradox derives a contradiction from noting that one has excellent though non-conclusive reasons for thinking that one's own ticket will lose, and thus reasons for thinking that every ticket will lose, despite knowing that some ticket will win. The preface paradox derives a contradiction from rational belief in each statement in a book, combined with the author's expression of modesty in the preface that because of the difficulty of the subject matter, errors are sure to be found in what has been written. 
need both to endorse the doctrines of the faith tying alethic and salvific adequacy and also believe the pluralist commitment that all such doctrines are false. The proper analogy here isn't the existentially quantified preface claim, but the universally quantified one: believing that all the claims in the book are false. So no mileage can be gotten from the attempt to solve the problem for pluralists raised by the Buridan's ass paradox by appeal to the lessons of the paradoxes.

Moreover, even though there are accounts of the nature of belief on which a person can rationally believe, e.g., that Cicero was a great orator while denying that Tully was, such examples of rational contradictory beliefs hold only because of the opacity of belief contents that exist in such cases: the person in question is unaware that Cicero is Tully. No such opacity is present here, so such examples are no help in rescuing pluralism from the problem generated by the Buridan's ass paradox.

So the problem remains and is pressing, leaving only the hope that the dogma tying alethic and salvific adequacy, which religions tend to preach, will not be included among the cognitive commitments essential for salvation. In order to avoid revisionary attitudes toward religion, pluralists will need to look for attitudes of optionality regarding such dogmas in the religions themselves. It is part of the pluralist trademark to leave religions as they are rather than to try to revise them in a way that more accurately reveals their purported logical core. The latter view is a version of revisionism, not pluralism; so, the pluralist will need to hold out the hope of finding attitudes of optionality within the religion itself in order to adhere to it without contradiction.

Requiring the finding of such a religion does not sit well with the respect pluralists intend to maintain for at least the major religions of the world. Pluralists think religions, at least the major ones, are fine as they stand, but the major religions simply do not reflect the kind of optionality required for pluralistic rational commitment to them. The pluralist seeking rational attainment of heaven needs a religion that requires belief in nothing incompatible with the pluralist stance in order to avoid the cognitive dissonance that would prevent the rational commitments necessary for allegiance to a religion. The attempt to commit to a religion on pluralist grounds thus becomes the attempt to find a religion that has only cognitive commitments consistent with those the pluralist thinks are true. In so doing, however, the pluralist 
will have ruled out most of the major world religions. Moreover, the pluralist will have begun the search for a religion worth having in the quite straightforward way of looking for a true one, using whatever resources are available, including one's view that alethic adequacy and salvific adequacy are unrelated. In short, the religious pluralist has to hope to find a religion that requires no cognitive commitments, no particular way of seeing, understanding, and experiencing the universe and our place in it.

This difficulty of describing how a pluralist could rationally attain heaven results from the insolubility of the Buridan's Ass paradox when applied to situations requiring cognitive commitments. When faced with such a situation, one's only recourse for doing anything that will have as a direct and immediate consequence the forming of the requisite beliefs is to try to find out what the truth is. That is how human beings go about forming beliefs. We could, I guess, go to Mass and hope for the best, or some analogue of such for religions other than Christianity, but that is not to have made a decision that resolves the paradox. It is only to do something which one hopes will result in forgetting one's pluralism while at the same time becoming convinced of the claims of the religion in question. A genuine pluralist adherent of a religion is possible only when a universal core of religions is found and some such version of a religion develops in response to perceived difficulties with the more typical exclusivism found in the major religions. In the absence of such a development, the Buridan's ass paradox undermines the possibility of rational pluralist salvation.

The same issues would arise for any arbitrary choice of which creeds to begin endorsing verbally. One might start talking like an adherent of a religion, with the idea that doing such will someday result in a commitment to the view. But in all such cases, the strategy is effective only if the pluralists forget their pluralism. The pluralist will have to forget that the particular religion one is hoping to achieve commitment to is no better than some others, and thus that the propositions which one hopes to come to believe that are incompatible with propositions constitutive of other religious points of view are not really true. So a fully informed and rational individual will simply be unable to commit in such a way as to secure heaven, for that is available, according to pluralists, only to those committing to some religion or other. 


\section{A Notion of Commitment for Pluralists?}

This problem has its source in the distinction between the cognitive situation involved in religious commitment and the merely practical commitment needed for the ass to keep from starving. The ass doesn't need to hold any beliefs; all that is needed is a decision. But it looks as if the pluralist needs beliefs, and in any case, it looks like the pluralist needs something beyond a mere decision in favor of one religion over another.

This diagnosis of the issue is demanded by the non-revisionary character of pluralism. Without such a non-revisionary stance, one might diagnose the issue in different ways. Revisionary approaches might question the idea that cognitive commitments to any religion are necessary for eternal blessedness or that cognitive commitments are essential to religion, regardless of what these religions might claim about themselves. The former view is at odds with the presupposition of pluralism that religion is central to the good life, and though the second idea might gain some support from efforts in the last century of moral theory which attempt to give non-cognitive construals of the apparently cognitive details of morality itself, the revisionary scent of such a proposal is still overwhelming. For even if such an account could be defended regarding the moral aspect of a religion, it is obvious that there is much more to a religion than its moral component, and the appeal to the prospects for non-cognitivism in ethics would be nothing more promising than the bizarre proposal that there is hope that all odd numbers are prime because the first four are. So the conclusion that bears repeating is that pluralists, unlike revisionists, want to respect religion as it is, rather than replace it with something more philosophically respectable.

We are thus left with the diagnosis above, that the difficulty encountered arises because of the difference regarding the cognitive commitments needed in the matter of religion versus starvation. This diagnosis is a useful one for the pluralist as well, since it suggests a possible avenue of escape from the difficulty posed. Standard epistemological approaches to cognition emphasize mental states such as belief and experience, but there is little reason to suppose that these attitudes tell the entire story of cognition. One of the more interesting related attitudes is the attitude of acceptance, an attitude that one adopts toward a proposition, assenting to 
its truth, committing oneself to acting on that proposition and defending it in the face of reasonable challenges. Any adequate psychology will have to endorse a distinction between belief and acceptance. Perhaps in the ideal case, all acceptances are believed to be true, but there is little reason to think that one cannot believe things that one does not accept and accept things that one does not believe.

Philosophical viewpoints are a good example of the latter. For example, one might accept classical logic, rejecting intuitionistic logic, but not actually believe anything here. At the very least, a realistic assessment should deny knowledge of such propositions, and some reflective philosophers strive to believe only what they know to be true. They nonetheless accept certain philosophical claims, refusing to stymie their discipline by refusing to accept anything that they don't know to be true. If their hopes are realized, they accept what they do not believe.

Any psychology influenced by Freud will admit the possibility of beliefs in opposition to what one accepts. The process of therapy is supposed to make possible the discovery that the doxastic forces underlying behavior are different than the overt stories we tell ourselves about what we are doing and why we are doing it. In such cases, it would be possible to find out that what one accepts is in conflict with what one believes, where the beliefs in question are not readily transparent to casual reflection.

The distinction between beliefs and acceptances might offer a way out of the problem here for pluralists. Pluralists might claim that, though cognitive commitments are central to many religions, the commitments in question are not best conceived in terms of beliefs, but rather in terms of acceptances. They must admit, of course, that religions tend to speak rather uniformly of cognitive commitments in terms of belief and faith, but there is no reason to expect any great philosophical precision to the terminology in question. Characterizing religious commitments in terms of acceptance rather than belief may require some slight revision of actual religion, but not an objectionable sort of revision. In this regard, it is important to note that the line between respect for religion as it stands and revision is a vague one, since the boundaries of any particular religion are themselves not precise and reflective adherents of a religion often change it for the better. It is relatively easy to see that adherents of religions that require cognitive commitments could maintain orthodoxy while proposing that the kind of commitment in question is that of acceptance rather than 
belief, so there is little reason to classify such a suggestion as requiring a revisionary attitude toward religion rather than a pluralistic one.

The advantage in the present context of emphasizing acceptance over belief for the pluralist is that acceptance is much more of a voluntary matter than is belief. What one accepts is more a matter of how one chooses to organize one's life, what claims to "go to bat for," which alternatives to argue against, and which stances to advocate both publicly and privately, all of which are obviously voluntary. Moreover, it is hard to see what objection particular religions might have to such a proposal. Consider traditional Christianity, for example. Though many religions use the language of belief to describe what is required for salvation, the point of such language is found in the contrasting state of unbelief. If a person accepts the claims of Christianity in the sense described above, they defend the faith, live by it (within the usual caveats about the compatibility of saving faith even in the face of continued displays of fallen human nature), and approach all of life from its perspective. The discovery of one whose commitments were of this nature, but who did not actually believe any of it, is not a possibility addressed in the theologies in question, but damnation for such would seem to be callous beyond belief.

Of course, one cannot rule out the possibility that some particular religion, or version of a religion, would object to this pluralist ploy of substituting acceptance for belief. My claim, however, is that the pluralist can take some refuge in the distinction and that doing so does not automatically force one to become objectionably revisionistic about actual religion. In this way, a pluralist can show respect for actual religious practice while at the same time avoiding the unsavory result of succumbing to the Buridan's ass paradox. By emphasizing acceptance rather than belief, the pluralist can claim that one can adopt one religion over another in precisely the same way that the ass selects one bale from which to eat. The choice may be arbitrary, but arbitrariness in the sense in question is not incompatible with rationality.

To evaluate this suggestion, it is important to see its formal features. The idea is this. There's a difference between action and belief in that the former is voluntary and the latter is not (or at least can't be relied on to be). There is also a difference in the kind of arbitrariness tolerable in rational cases of each sort. In both cases, reasons don't have to be contrastive reasons, but one can't have rational beliefs without being in a position to 
rule out known competing alternatives ${ }^{12}$ whereas one can have rational actions even in the face of such alternatives. The hope involved in the pluralist's attempt to substitute acceptance for belief is that the latter normative difference supervenes on the former factual difference. That is, the hope is that because actions are voluntary and beliefs are not, rationality in the arena of action can be arbitrary in a way that it cannot be in the arena of belief.

This way of trying to rescue the pluralist from the problem arising from the Buridan's Ass Paradox is far from compelling, however. First, let me offer the reader the chance to share my own reaction that the explanation in question is utterly mysterious. According to this account, what makes rationality less restrictive in the domain of action than in the domain of belief is that voluntariness is present in the former but not in the latter. When such a suggestion is made, I experience perplexity. Why would one think this? How does the voluntariness point have the implications claimed? The point is far from obvious, and I don't see any plausibility to the claim at all. I hereby invite the reader to share in this perplexity.

Moreover, there is an alternative explanation to consider. If we think about the notion of rationality applying to various kinds of mental states as well as to actions, we may think in terms of direction of fit to carve a distinction among items rationally evaluable. For some such items, the direction of fit runs from world-to-item. The classic example here is belief: beliefs are supposed to represent the world as it is (in the sense that the goal of belief is truth), so the normative direction of fit runs from world to belief. The classic example of the other direction is desire: desires tell us how we want the world to be, not how it is, so the direction of fit runs from desire to world. Since actions function as the outward expression of inner items whose direction of fit runs from item to world (an expression of our wants, wishes, hopes, fears, and desires), actions too are best conceived in terms of item-to-world direction of fit.

If we use the language of connative versus cognitive items to describe this distinction, we can find an alternative to the above account in terms of voluntariness. Instead of claiming that the more voluntary an item happens to be, the less restrictive the demands of rationality on that item, we can

${ }^{12}$ For an account of this notion of being in a position to rule out known competitors, see Peter Klein, “Closure Matters: Skepticism and Easy Knowledge," Philosophical Issues I4 (2004), pp. I65-I84. 
say that the less restrictive demands of rationality apply in the connative realm but not in the cognitive realm. This alternative explanation prevents the pluralist from escaping the problem arising from the Buridan's Ass Paradox by appeal to the distinction between acceptance and belief, since even though acceptance may be more voluntary than belief, it still falls on the cognitive side of the divide between the connative and the cognitive. For acceptance just as much as for belief, the appropriate direction of fit runs from world to item rather than the other way around.

It is important to note here that the notion of acceptance is not simply a behavioral notion. It, like the notion of belief itself, is assumed not to be susceptible to behavioral analysis. This point is important, for if it were explicable in this way, accepting the claims of a religion would involve no cognitive commitments at all. In such a case, replacing the notion of belief in religious commitments with the notion of acceptance would simply be the proposal that acting as if the claims in question are true is enough for sincere adherence to a religion, and such a proposal is surely too revisionist for a pluralist to adopt. It is thus crucial that, though acceptances explain some of our behavior, they are not reducible to it. Regarding this proposal concerning direction of fit, the experience of perplexity may be in order. To say that the direction of fit is what makes for greater or less restrictiveness regarding rationality is to say something every bit as mysterious and uncompelling as to insist on an explanation in terms of voluntariness. Neither suggestion comes accompanied by a feeling of insight or the satisfaction we experience when finally achieving understanding.

Let me be clear that the failure to be accompanied by these psychological phenomena does not show that either proposal is mistaken. The probative value of such points is much weaker than that here. But these points are relevant nonetheless, since they describe the kind of ideal explanation we seek regarding any phenomenon, and so the failure to obtain such an explanation here gives us some reason, however small, to continue wondering whether there is a more revealing explanation to be had.

If we extend our search for an explanation of variations in the restrictiveness of rationality beyond those that appeal either to voluntariness or direction of fit, I believe there is just such an explanation available. I think the correct story to be told is that the default setting for rationality is equally restrictive always and everywhere, but that this setting is only 
a default setting rather than an unalterable one. The kind of rationality to which this point applies is the rationality of mental states and actions (though of course there are mental states, such as experiences, to which the notion does not apply). For each such item, there are at least three settings possible. For belief, for example, there is belief, disbelief, and withholding. For action, there is performing the action, performing a contrary action, and doing nothing. For connative states, such as desire, the story is similar to that of belief: there is desiring that a state of affairs obtain, desiring that the state of affairs not obtain, and being neutral regarding the obtaining of that state of affairs. We can thus identify these three possible settings as a positive setting, a neutral setting, and a negative setting.

In general, when the rationality-conferring factors present are equally weighted between the positive and negative settings, the rational setting is the neutral setting. That is the default position described above. But in certain cases, there can be a meta-reason present as to why the neutral setting is the worst option of all, as in the Buridan's Ass Paradox. Rationality here is understood teleologically, leaving open the possibility that a meta-reason is present for thinking that even though the positive and negative settings are equal as means to the goal in question, the neutral setting can be ruled out because it is so counterproductive to the goal in question. Thus, in cases of action in which delaying action to gather more information is not problematic, the fact that two competing actions are tied in terms of effectiveness at achieving the goal of well-being doesn't leave one free to perform either action and still be rational. The third, neutral setting wins out in such situations. But in cases where there is a meta-reason against the neutral setting, then the restrictive default setting must give way. The Buridan's Ass Paradox is just such a case, where the meta-reason in question is that adopting the neutral stance to gather more information results in starvation, which is as obviously contrary to the goal of well-being as anything can be. So the default restrictiveness built into the notion of rationality is overridden by this meta-reason.

It is an interesting question whether such a meta-reason could be found in a purely cognitive case involving belief. Such a reason would have to be a reason for thinking that the option of withholding was so contrary to the achievement of the epistemic goal that one should either believe or disbelieve in spite of having no good reason to favor either 
view over the other. The possibility of such cases, however, appears to be undermined by the fact that the epistemic goal is dual in nature. It involves both getting to the truth and avoiding error, implying that the only meta-reason there could be for overriding the default restrictiveness of the notion of rationality would be a reason for thinking that failure to believe or disbelieve would undermine one's ability both to get to the truth and avoid error.

It is hard to imagine any possible situation in which there would be such a reason, and if so, we should expect the default setting of restrictiveness concerning rational belief to hold sway in every possible case. But perhaps there could be a meta-reason that shows that the default setting does not always hold sway. For reflective individuals, the question often arises whether to trust one's cognitive abilities to discern truth from error in a particular domain of inquiry. Such a question is one with answers in terms of degree of trust warranted, rather than only answers in terms of whether or not to trust. When the question of self-trust arises, the possibility of a paralyzing effect arises if we imagine the person unable to commit to some particular answer to the question of how much self-trust is appropriate. Suppose you assess the evidence for a given claim $p$ as overwhelmingly positive, but you also claim to have no idea whether you are worthy of self-trust in assessing the truth-value of $p$. If your attitude was that you slightly overestimate the force of the evidence for claims such as $p$, you could still rationally accept $p$. If your attitude was that you are always wrong about such matters, confusing reasons for $p$ with reasons against $p$, then you could rationally disbelieve $p$. But so long as you withhold on whether you are deserving of any trust at all about such matters, so long as you take the position that full neutrality on whether you are trustworthy is the best position to hold, you have eliminated all hope of achieving the epistemic goal. You are paralyzed, rationally speaking.

So perhaps any attitude you take would be epistemically preferable from a purely epistemic point of view to this situation of paralysis. Unlike the practical situation, however, you cannot resolve the paralysis simply by making a choice to believe or disbelieve. But you may be able to choose whether to accept or dis-accept, and in so doing, set in motion chains of causal influence that result in beliefs of various sorts, beliefs that are thereby rational or irrational in virtue of whether they are appropriate means to the epistemic goal. 
I offer this example of self-trust, though, only as a possibility, ${ }^{13}$ for nothing turns on the question of whether analogues of the Buridan's ass situation are possible in the cognitive sphere. If they are not possible, then the restrictive default setting of rationality can only be overridden in the practical sphere and not in the cognitive sphere. Even so, we will have an explanation of why rationality is less restrictive in some areas than in others without having to conclude that there are different notions of rationality at work in the two areas. It would be the same notion of rationality at work in both arenas, with the differences resulting from the impossibility of the existence of certain types of meta-reasons in the cognitive sphere. I myself am attracted to the idea that issues about self-trust show that such meta-reasons are possible in the cognitive sphere, but nothing turns on whether this idea is correct.

\section{Conclusion}

This account of the matter renders the appeal to the distinction between acceptance and belief impotent to save the pluralist from the difficulty caused by the Buridan's Ass Paradox. The fact that acceptance is voluntary doesn't take us any distance at all in showing that there is a rational resolution available to the pluralist who thinks that all religions are equally good. For to accept the claims of a religion is to accept them as true, and this the pluralist cannot rationally do except by abandoning his pluralism or corrupting it with revisionary tendencies toward actual religions.

There remains a residual feeling, however, that there is something that this pinning of the pluralist leaves out. It is the idea that mental states can be evaluated in terms of either the practical notion of rationality or the epistemic notion of rationality. All the above shows is that there is no epistemically rational way of escaping the problem raised for the pluralist by the Buridan's Ass Paradox, but it doesn't show that there is no practically rational way of escape. Since beliefs aren't voluntary, the fact that it would be practically rational to believe some religion or other can't eliminate the problem, since such features don't typically prompt

${ }^{13}$ For extended discussion of the notion of self-trust and a defense of its centrality in the story of epistemic justification, see Keith Lehrer, Self Trust: A Study of Reason, Knowledge and Autonomy (Oxford: Oxford University Press, 1997). 
belief. But since acceptance is voluntary, the practical considerations in question give one a practical reason to voluntarily accept some religion or other, and the pluralist can do that.

Though this point is correct, it ignores the way in which love of truth is central to religion. In Christianity, for example, the points about purity of heart and counsel against double-mindedness include alethic elements, so that engaging in religious practices while not doing so in virtue of the perceived truth of the view is a defect that needs to be overcome at some point in order for the promise of the beatific vision to be achieved. Given the centrality of such features of religion, the practical solution to the pluralists' dilemma is a solution adopted for the purpose of losing one's pluralist perspective in the process. It is thus a resolution of the dilemma only to the extent that it begins a process wherein the pluralist ceases to be one, for only in such a process can the great goods religion offers be appropriated. As such, it is not a pluralist solution to the dilemma, but rather a practical solution to the defect of finding oneself with pluralist views. A pluralist can escape the Buridan's ass problem for pluralism with a practical decision, but the solution will not be a solution to the problem for pluralism, but rather a potential way of getting out of the problem by taking steps to abandon one's pluralism. Such a solution is available in other ways as well, by evaluating the plausibility of the pluralist view itself and coming to see that it is false. But such a recommendation would not count as a solution to the Buridan's ass problem for pluralism, but rather a recommendation for how to avoid that problem by avoiding the pluralist views that generate the problem. As such, pluralism itself remains lost at sea, even though those who hope to become former pluralists need not despair. 